\title{
Study on Chemical Composition of Super Napier Grass Silage Treated with Lactobacillus Buchneri and
}

\section{Lactobacillus Plantarum}

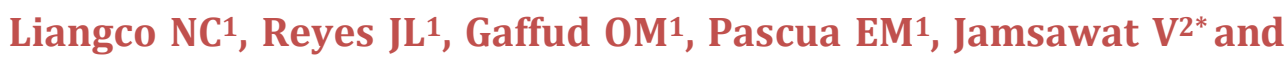 \\ Seatung $\mathrm{C}^{2}$ \\ ${ }^{1}$ Isabella State University, Philippines \\ ${ }^{2}$ Rajamangala University of Technology Tawan-ok, Thailand
}

*Corresponding author: Virapol Jamsawat, Faculty of Agriculture and Natural

\begin{tabular}{|c|}
\hline Research Article \\
Volume 2 Issue 2 \\
Received Date: October 26, 2019 \\
Published Date: December 19, 2019 \\
DOI: 10.23880/oajmms-16000109 \\
\hline
\end{tabular}

Resourse, Rajamangala University of Technology Tawan-ok, Thailand, Email: virapolj@yahoo.com

\section{Abstract}

The research was aimed to study on chemical composition of super Napier grass silage treated with Lactobacillus buchneri and Lactobacillus plantarum.

The result showed that super Napier grass (SNG) silage treated with inoculants had higher levels of crude protein, crude fiber, crude fat, crude ash and nutrient detergent fiber compared with the untreated super Napier grass treated. The DM fraction of the SNG treated silages was increased in contrast to the untreated where the moisture content increased.

The experiment trial indicated that SNG silage treated with Lactobacillus buchneri and Lactobacillus plantarum (T2 and T3) influenced. Thus, addition of beneficial microbes improves the nutritional quality of silage and increased nutrients levels. However, more research is needed to elucidate the mode of action of SNG treated silages

Keywords: Super Napier Grass Silage; Lactobacillus Buchneri and Lactobacillus Plantarum

Abbreviations: SNG: Super Napier Grass; LAB: Lactic Acid Bacteria; ABW: Average Body Weight Gain; ADG: Average Daily Gain; DM: Dry Matter; FCR: Feed Conversion Rate; CRD: Completely Randomized Design; LSD: Least Significant Difference; VFA: Volatile Fatty Acids.

\section{Introduction}

Inadequate feed and poor quality of forage crops in the country (Philippines and Thailand) are the major constraints to the development of ruminant animal industry. To solve these problems, feeding ruminants with conserved forages which is becoming popular among enterprising livestock raisers in the country is an important feeding strategy to ensure the success of ruminant production [1]. Ruminant animals has the ability not only to survive different environmental conditions but also able to utilize poor quality feed.

Feed resources for ruminant production in the country normally are natural forage crops or natural pastures and poor quality of grasses which are limited in supply during the dry season. Today, ruminants are now fed with 


\section{Open Access Journal of Mycology \& Mycological Sciences}

preserve feeds especially with dairy and beef cattle that require high level of nutrition in order to achieve high milk production. Nowadays, the use of corn silage and other crops as green forage in ruminant feeding has increased rapidly due to its high yielding properties, high energy content, highly digestible, palatability and easy incorporation in total mixed ration. Scarcity of feed for ruminants is one of the important problems for rearing livestock during summer especially in the country and other tropical countries [2]. However, livestock raisers can conserve feed resources by producing silages when feed resources are abundant during rainy season. Since silage is an alternative for ruminants especially in production situations that require consistent nutrition on a daily basis, condition of silage has a significant impact on its quality for reasons that forage often contains many detrimental types of bacteria. In fact, the primary goal of making silage is to maximize the preservation of original nutritional value of the forage crop at the highest value possible during storage for feeding at a later date. The traditional method of fermentation in the silo however, is a much uncontrolled process usually leading to less than optimal preservation of nutrients.

The concept of adding a microbial inoculant to silage was to add fast-growing homo fermentative lactic acid bacteria (LAB) in order to dominate the fermentation resulting in higher quality silage [3]. Lactobacillus buchneri and Lactobacillus plantarum are some of the most common LAB inoculants in the fermentation of silage. Poorly preserved silages have poor fermentation quality; they are unpalatable to stock and reduced feed intake. These silages are also likely to have suffered extensive degradation of protein, resulting in poor utilization of the silage nitrogen by animals. In order to assist in the fermentation process, various silage additives have been used to improve the nutrient and energy recovery in silage, and when fed to livestock it will subsequently improve animal performances. The different species of lactobacillus were tested to find out the effectiveness of the lactobacillus species as additives in ensiling "super Napier" known as "Pakchong 1" which was developed and produced in Thailand. The "Super Napier Grass" (SNG) is a cross of ordinary Napier grass (Pennisetum purpureum) and Pearl Millet (Pennisetum glaucum) can yields more crude protein of about 16 to 18 percent [4]. This grass requires lower inputs and easier to establish compared to corn and can be a good alternative, especially in production situations that require consistent nutrition on a daily basis. It is for this reason that two silage additives were tested to find out the effectiveness of preserving the quality of super Napier grass.

\section{Methodology}

\section{Procurement and Preparation of Inoculants}

The L. buchneri and L. plantarum additives that were used in this experiment were purchased in Korean Culture Collection of Microorganism. Cultures that was cultivated anaerobically in De Man, Rogosa and Sharpe (MRS) agar medium in $250 \mathrm{ml}$ flasks incubated at $30^{\circ} \mathrm{C}$ for 2 day in an orbital shaker (Thermo Scientific Max Q 2000, USA) at $100 \mathrm{rpm}$. Cultures were diluted in demineralized water before use. Inoculant was added at a theoretical rate $1.0 \times 10^{5} \mathrm{cfu} / \mathrm{g}$. prior to inoculation, inoculant will be diluted with distilled water to achieve the required concentration and keep for silage production.

\section{Gathering of Super Napier Grass and Preparation for Ensiling}

Super Napier grass was sourced out from Isabella State University, Echague, Isabella farm. The SNG was manually harvested at the maturing stage approximately 80 to 90 day of regrowth and was chopped into 2-3 centimeters.

Fifteen plastic drum silos with a capacity of $20 \mathrm{~L}$ were randomly assigned to three treatments by four factors experiment. The SNG were ensiled into 20 -L drum silo and stored in dark and ambient temperature $\left(5^{\circ} \mathrm{C}-10^{\circ} \mathrm{C}\right)$ for $0,7,15$ and 30 days. The treatments were the following:

- Treatment 1-(control)-Super Napier Grass without inoculants.

- Treatment 2-Super Napier Grass treated with Lactobacillus buchneri.

- Treatment 3-Super Napier Grass treated with Lactobacillus plantarum.

\section{Ensiling Procedure for Super Napier Grass}

Fifteen kilogram of SNG grass each replication were inoculated with or without $3 \%(\mathrm{w} / \mathrm{v})$ of L. buchneri or $L$. plantarum through spray method followed by thorough mixing. The samples were ensiled into 20 -L drum silo and stored in dark and ambient temperature for $0,7,15$, and 30 days. Triplicate silos were opened and the upper part $1 / 5$ of silages was discarded before sampling of approximately $100 \mathrm{~g}$. after each incubation period. Silage extracts will be prepared immediately by macerating a 50 g. silage samples with a $300 \mathrm{ml}$. of distilled water. These were collected through double cheesecloth and used to determine $\mathrm{pH}$ value and concentrations of volatile fatty acids (VFA) and volatile basic nitrogen and ethanol. Dry 
matter (DM) content of grass and silages were determined by a vacuum freeze-drying method [5]. The dried samples were grinded and then the crude protein was determined by the Kjeldahl method. NDF, ADF, and ADL were measured by the method of Goering, et al. [6]. Water soluble extracts was prepared by macerating $40 \mathrm{~g}$ of fresh silage sample in $400 \mathrm{ml}$ distilled water. The $\mathrm{pH}$ of the extracts was measured by using electric $\mathrm{pH}$ meter (PH71/PH72 personal pH/ORP meter, Yokogawa Electric Corporation, Japan). Fermentation products, $\mathrm{pH}$ and ammonia were determined in silage extracts, prepared by adding $270 \mathrm{~g}$ demineralized water to $30 \mathrm{~g}$ silage and homogenizing for $5 \mathrm{~min}$ in a laboratory blender. Volatile fatty acids were analyzed using an HPLC device (Agilent Technologies 1200 series).

\section{Data Gathered and Statistical Analysis}

The chemical analysis of SNG and the chemical analysis of super Napier grass silage were determined, recorded and served as basis of evaluating the quality of silages as affected by the different additives/inoculants. All data gathered were tabulated and analyzed using analysis of Variance in Completely Randomized Design (CRD). Significant differences among treatments were also analyzed using the Least Significant Difference (LSD).

\section{Results and Discussion}

\section{Chemical Analysis of Super Napier Grass}

The chemical analysis of SNG was shown in Table 1. Results of the chemical analysis of super Napier grass as fresh and as dry matter bases were analyzed. The fresh basis analysis was as follows: crude protein content was $1.21 \%$, crude fiber, $5.37 \%$, crude fat, $10.12 \%$, moisture, $85.09 \%$, Ash, $1.01 \%$ and neutral detergent fiber, 10.20 percent. Likewise, the analysis as dry matter basis were as follows: crude protein content, $8.12 \%$, crude fiber, $36.02 \%$, crude fat, $67.87 \%$, ash, $6.87 \%$ and neutral detergent fiber, $68.41 \%$.

\begin{tabular}{|c|c|c|}
\hline Parameters, \% & Fresh, \% & Dry Matter, \% \\
\hline Crude Protein, \% & 1.21 & 8.12 \\
\hline Crude Fiber, \% & 5.37 & 36.02 \\
\hline Crude Fat, \% & 10.12 & 67.87 \\
\hline Moisture, \% & 85.09 & - \\
\hline Ash, \% & 1.01 & 6.77 \\
\hline Neutral Detergent Fiber, \% & 10.2 & 68.41 \\
\hline
\end{tabular}

Table 1: Chemical Analysis of Super Napier grass.

The chemical analysis used in this study is below the findings of percent with a CP concentration of 16-18 percent of a 45 days cutting interval [4]. The low CP concentrations of Napier grass was attributed to the high structural cell wall carbohydrates that increase rapidly with maturity causing decline in $\mathrm{CP}$ concentration and digestibility. Also demonstrated the effects of cutting interval on yield and quality vary with cultivars management practices and environmental conditions. Therefore, appropriate cutting management is essential for high production and quality of this species [7].

\section{Chemical Analysis of Untreated and Treated Super Napier Grass Silage}

The chemical analysis of SNG treated and untreated (DM basis) was shown in Table 2. Results of the analysis of the different silages treated and untreated varied among the treatments. After 7 days of fermentation, it was observed that the level of crude protein content of silage treated with inoculants had increased by $20 \%$ in T2 and
$16 \%$ in $\mathrm{T} 3$, while those silage treated with plain water, (T1) had a reduction of 19.17 percent. Similar observation of improvement with silages treated with inoculant was noted on crude fiber, ash and neutral detergent fiber. The $\mathrm{pH}$ level prior to ensiling ranged from 6.5 to 7.0 and at the end of 30 days fermentation, the $\mathrm{pH}$ level drop due to lactic acid production with $\mathrm{pH}$ ranged from 4 to 4.5 . The variation on the $\mathrm{pH}$ levels was probably due to the different inoculants used. It is worthy to mention that at the end of the $30^{\text {th }}$ day of fermentation nutrient levels was improved. There was a noticeable improvement of ash and crude fiber content in all treatments, treated or untreated. Although there was a slight reduction on the crude protein content of SNG in all treatments from the start, the crude protein content of the treated silages were higher than the untreated ones. On the other hand, there was a substantial increase of crude fat in the untreated silages compared to the treated silages; however, at the end of 30 days of fermentation, there was a marked increase in the level of crude fat in treated silages higher than the untreated silages. 


\section{Open Access Journal of Mycology \& Mycological Sciences}

\begin{tabular}{|c|c|c|c|c|c|c|}
\hline \multirow{2}{*}{ Parameters } & \multicolumn{2}{|c|}{ T1-w/o inoculant } & \multicolumn{2}{c|}{ T2-Lacto. Buchneri } & \multicolumn{2}{c|}{ T3-Lacto. Plantarum } \\
\cline { 2 - 7 } & Day 0 & Day 7 & Day 0 & Day 7 & Day 0 & Day 7 \\
\hline Crude Protein, \% & 2.66 & 2.15 & 1.72 & 2.07 & 2.24 & 2.59 \\
\hline Crude Fiber, \% & 5.79 & 5.17 & 5.23 & 6 & 5.17 & 6.92 \\
\hline Crude Fat, \% & 1.09 & 13.55 & 2.47 & 1.39 & 8.88 & 1.29 \\
\hline Ash, \% & 2.28 & 1.93 & 1.93 & 2.21 & 1.51 & 2.09 \\
\hline NDF, \% & 11.69 & 10.31 & 11.96 & 13.06 & 10.84 & 12.56 \\
\hline Dry Matter, \% & 82.05 & 84.33 & 83.17 & 81.08 & 83.93 & 80.9 \\
\hline
\end{tabular}

Table 2: Chemical composition of untreated and treated SNG silage with bacterial inoculant at DM basis.

The result of the study conforms to the main objective of manufacturing silages which is to maximize the preservation of original nutrients in the forage crop for feeding. The result likewise confirmed reports that fermentation is really an uncontrolled process usually leading to less than optimal preservation of nutrients. The used of inoculants is therefore necessary to assist in the fermentation process. Silage additives have been used to improve the nutrient and energy recovery in silage, and when fed to livestock it will subsequently improve animal performances [3]. In conclusion, these studies confirmed that the applying of molasses improved fermentative quality, feed intake and digestibility of Napier grass [8].

The graphical presentation of the untreated and treated Super Napier grass is illustrated in Figures 1-3. The moisture content in T1-control increases as fermentation progresses then dropped starting on the $15^{\text {th }}$ day to $30^{\text {th }}$ day of fermentation. Whereas, the treated silages decreases consistently from day 7 to day 30 of fermentation. It is interesting to note that there were clear differences on the nutrient levels among the different treatments with higher levels in the treated silages. The illustration is a clear indication that nutrient levels in silaging is improved and preserved as manifested by the absence of mold. The result of this study is supported by Driehuis, et al. [9] in corn silage treated with L. buchneri was more stable than untreated silage. They suggest that improved aerobic stability was due to the ability of L. buchneri to ferment lactic acid to acetic acid and 1, 2 propanediol.

Although the results are encouraging, it should be noted that other literature reports varied markedly among due to environmental factors. The variability in results from this experiments involving silage fermentation indicates that further evaluations are necessary to broaden the database of additives for the ensilage of super Napier grass.

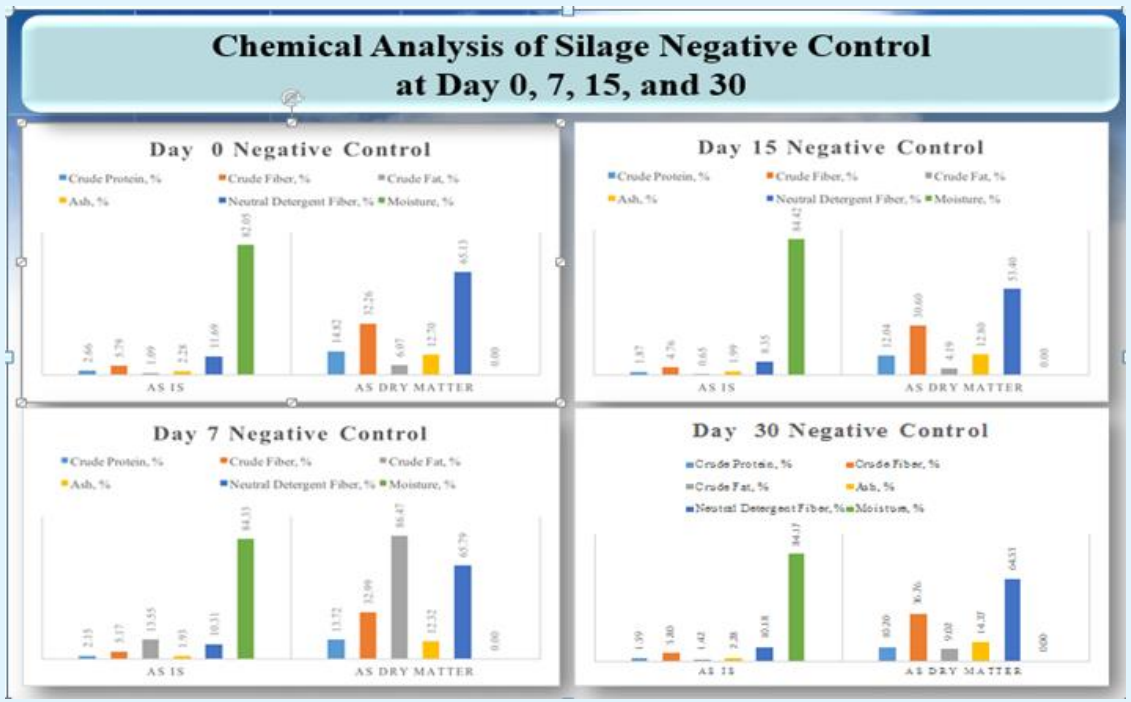

Figure 1: Graphical presentation of super Napier grass silage treated with plain water (control) from day 0 to day 30 of fermentation. 


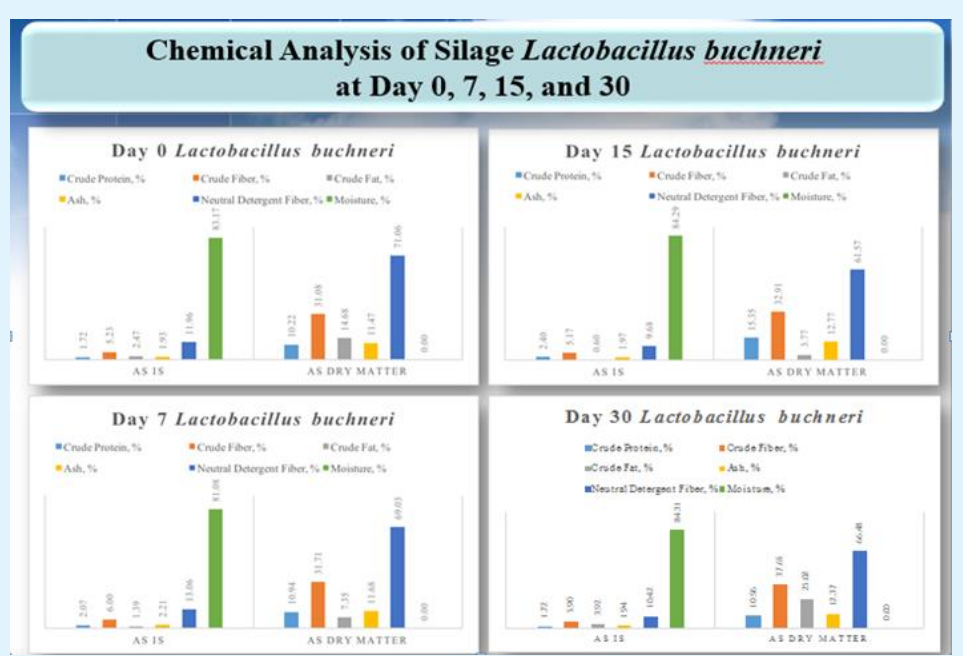

Figure 2: Graphical presentation of super Napier grass silage treated with L. buchneri from day 0 to day 30 of fermentation.

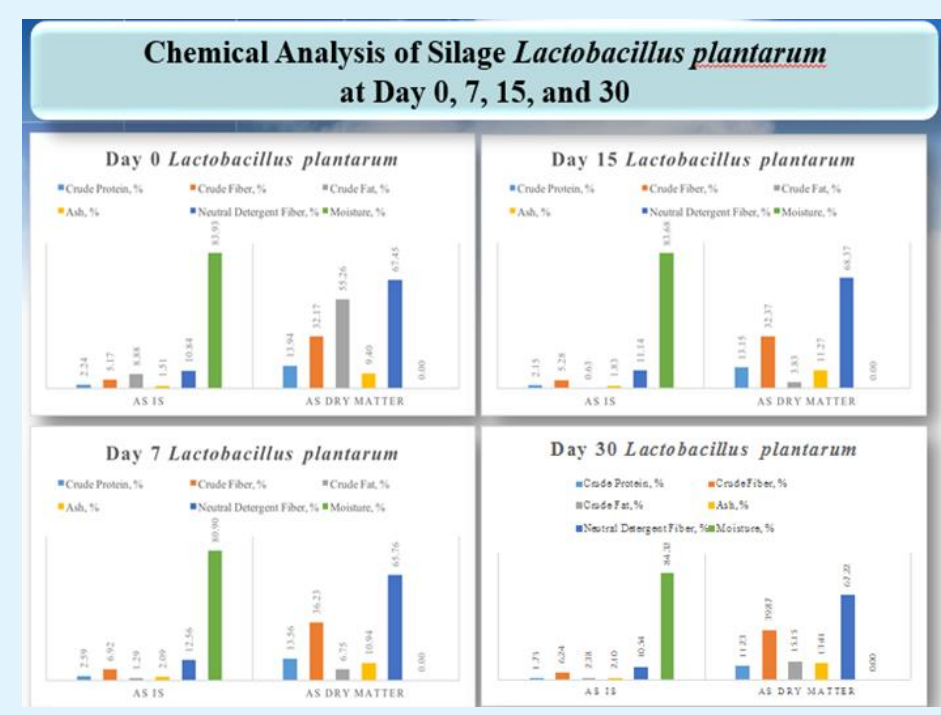

Figure 3: Graphical presentation of super Napier grass silage treated with L. plantarum from day 0 to day 30 of fermentation.

\begin{tabular}{|c|c|c|c|c|}
\hline \multirow{2}{*}{ Treatments } & \multicolumn{4}{|c|}{ Ave. Bi-weekly Body Weight (BW) Gain (kg.) } \\
\cline { 2 - 5 } & Body Weight. Gain (kg.) & ADG, Grams & DM intake (kg.) & FCR (DM) \\
\hline 1-Control & $4.25 \mathrm{~b}$ & $60.72 \mathrm{~b}$ & $47.71 \mathrm{~b}$ & $8.94 \mathrm{~b}$ \\
\hline 2-Lacto. buchneri & $5.60 \mathrm{a}$ & $80.00 \mathrm{a}$ & $50.35 \mathrm{~b}$ & $7.26 \mathrm{ab}$ \\
\hline 3-Lacto. plantarum & $5.80 \mathrm{a}$ & $82.85 \mathrm{a}$ & $51.20 \mathrm{a}$ & $7.21 \mathrm{a}$ \\
\hline Result & $* *$ & $* *$ & $*$ & $*$ \\
\hline \%C.V. & 3.98 & 6.5 & 5.79 & 10.24 \\
\hline
\end{tabular}

Means with common letter are not significantly different with each other using LSD.

Table 3: Average Body Weight Gain (ABW), Average Daily Gain (ADG), Dry Matter (DM) intake, and Feed Conversion Rate (FCR) of sheep fed with SNG silage. 


\section{Open Access Journal of Mycology \& Mycological Sciences}

\section{Result and Discussion}

Result of the study was similar with the studies conducted by Khaini, et al. [1]. Weinberg, et al. [10] described the effect of lactic acid bacteria (LAB) on animal performance that feeding cattle with silages treated with LABs improve ruminant performance [9]. Likewise, in several trials conducted by Spoelstra, et al. [11] and Muck, et al. [12] reported that inoculants exhibited substantial effect on performance on live weight gain, milk production, increase in intake and feed efficiency. This suggest the ensiling of SNG with microbial inoculants to improve the nutritional quality of SNG especially when there is abundant supply of grasses and feeding them to sheep during summer time when there is scarcity of roughages. In conclusion, these studies confirmed that the applying of inoculants improved fermentative quality, feed intake and digestibility of Napier grass [8].

\section{Conclusion and Recommendation}

The trial revealed that there is a great potential for improvement with the addition of beneficial microbes such Lactobacillus buchneri and Lactobacillus plantarum as it improves nutritional quality of SNG silage thus influenced feed quality and feed efficiency.

It is recommended that more research is needed to broaden the database of additives for the ensilage of SNG and to determine the nutrient digestibility and the combination of grasses to silage to reduce feed costs. Likewise, there is a need to find out if there is a deleterious effect to the end product's taste, tenderness, palatability and overall acceptability of animal production.

\section{References}

1. Khaini KT, Lothi TC, Ghizan S, Halim RA, Samsudin AA (2015) Feed intake, growth performance and digestibility in goats fed whole corn plant silage and Napier grass. Malaysia Agricultural Information Portal 18(1): 87-98.

2. Jamsawat V, Munkaew S (2017) Effects of using applied Mission grass as roughage for feeding dairy heifer. Rajamangala University of Technology Tawanok Research Journal 10(2): 139-144.

3. Kung L, Ranjit NK (2001) The effect of Lactobacillus buchnery and other additives on the fermentation and aerobic stability of barley silages. J Dairy sci 84(5): 1149-1155.

4. Kiyothong K (2014) Miracle grass seen to boost local dairy production.

5. Uchida IA, Freeman VC, Basrur PK (1986) The fragile $\mathrm{X}$ in cattle. Am J Med Genet 23(1-2): 557-562.

6. Goering HK, Van Soest PJ (1970) Forage fiber analysis (apparatus, regents, procedures and some applications) Agriculture Handbook. United states Department of Agriculture, Washington pp: 20.

7. Tessema ZK, Mihret J, Solomon M (2010) Effect of defoliation frequency and cutting height on growth, dry-matter yield and nutritive value of Napier grass (Pennisetum purpureum (L.) Schumach). Grass and Forage Science 65(4): 421-430.

8. Bureenok S, Yuangklang C, Vasupen K, Schobewille TJ, Kawamoto Y (2012) The Effects of Additives in Napier Grass Silages on Chemical Composition, Feed Intake, Nutrient Digestibility and Rumen Fermentation. Asian Australas J Ani Sci 25(9): 12481254.

9. Driehuis F, van Wikselaar PG (2000) The occurrence and prevention of ethanol fermentation in high-drymatter grass silage. J Sci Food Agric 80(6): 711-718.

10. Weinberg ZG (2013) Effect of Lactic Acid Bacteria on Animal Performance. Indian Journal of Biotechnology 2(3): 378-381.

11. Spoelstra SF (1992) Chemical and biological additives in forage conservation [1991]. Food and Agriculture Organization of the United Nations 123: 48-70.

12. Muck RE (1993) The role of silage additives in making high quality silage, in silage production from seed to animal. Northeast Regional Agric Engng pp: 106-116. 